\title{
The One and the Many: The Significance of the Labyrinth in Contemporary America
}

\author{
Mary Hackworth
}

\begin{abstract}
Unicursal labyrinths, with a single, highly circuitous path based on a medieval design, have enjoyed an unusual amount of interest in the United States over the last twenty years. They appear in such varied settings as churches, parks, hospitals, and retreat centers, their growing popularity coinciding with a time of deep political divisions in American society. The unicursal labyrinth closely resembles a mandala, suggesting that its current appearance is compensatory to the increasing fragmentation and growing diversity in American life. The labyrinth's popularity in meditative and recreational settings expresses a deepseated wish to walk a heroic, individual path and connect this path to a larger purpose. As socio-psychological theories of the individual's relationship to society move toward an "embedded" model, the labyrinth, too, suggests a collective, perhaps unconscious desire to find a middle way between individualism and common purpose as well as shared ground amid competing cultural values.
\end{abstract}

\section{Introduction}

The unicursal labyrinth, with its single, winding path, is an image encompassing both shared experience and a private and individual way of receiving that experience. Although the multicursal maze is often considered a more fitting symbol of modern life, unicursal labyrinths based on the medieval design have enjoyed a great resurgence over the last twenty years. The medieval labyrinth, which closely resembles Carl Jung's description of a mandala, has surfaced at a time of division and contention in American history and may be expressing a wish to integrate individualism and common purpose. It symbolizes a way out of the imbalance inevitable in a society that prizes individual initiative while relying on participation in democratic processes to thrive.

Although I believe that the labyrinth's increasing popularity worldwide is in some ways connected with the American trend, I am interested here in reasons for the phenomenon initiated in the United States largely by the work of Lauren Artress in the 1990s. In this hermeneutical study, I will outline a theory, based on recent sociological and political research on fragmentation, the Jungian conception of mandala symbolism, and the emerging idea of cultural complexes, to explain the transformation of the labyrinth from a rarity to an object numbering thousands of 


\section{Journal of Jungian Scholarly Studies 2}

installations in the United States alone. Several factors, including the erratic blend of individualism and community that characterizes American life, seem to be implicated in the medieval labyrinth's contemporary appearance.

\section{Individualists in Search of a Country}

The United States still celebrates the pioneers, explorers, and other "rugged individualists," mythic and real, of its founding. Nevertheless, the tension between the individual and the communal reveals itself in an uneasy dance between personal rights and the greater good (Thomson 631-33). Recent popular movies have expressed this tension, which runs like a leitmotif through the nation's history. The Marvel superhero movies, including Iron Man, Captain America, and Thor, all depict larger-than-life heroes with strong egos who battle villains. In The Avengers, we see the difficulties that arise when these outsized personalities unite to fight a common enemy. The film Lincoln portrays a similar tension in events surrounding the passage of the Thirteenth Amendment (to abolish slavery). Two stories emerge in American life: one asserts that there is no substitute for individual action, and the other insists that differences must often be submerged in pursuit of a greater goal.

Western idealization of the heroic individual has a long pedigree. Joseph Campbell identifies the thirteenth-century Queste del Saint Graal as a literary exemplar of the changing emphasis from reliance on authority (especially the Church's authority) to reliance on individual trial and error as the ideal path to knowledge (Creative Mythology 36-37). Americans are inheritors of this ideal; admiration for individual capacities and reverence for self-reliance are part of America's character as a nation.

Thomas Singer describes a series of "cultural complexes" that define America, among them the fundamental tension between individual rights and the greater good of the community, which surfaces in political strife over issues such as gun control and health care (167). In many cases, differing views on these matters align with liberal or conservative values, revealing the psychological dynamics behind the politics. Singer acknowledges the bitter conflicts these issues engender while pointing out that such debates are part of a meaningful struggle to craft policy and chart a course as a society. A related and no less important cultural complex involves America's struggle to define its place as a world citizen, a nation among others, with responsibilities as well as rights (170-71).

These complexes-autonomous, sometimes unconscious patterns of thinking and behaving based on past, traumatic experience and involving a great deal of collective emotion - are as old as the nation's origins. The United States was founded by emigrants from other shores, many of whom came seeking liberty from one form or other of oppression. Of course, the experience of those who arrived here in bondage or who were subjected to oppression from the newcomers is also 


\section{Hackworth}

part of the traumatic past and has shaped the story from the start, frequently giving Americans cause to question the truth of the freedom narrative.

Injustices notwithstanding, opportunity could be carved out in America, but at a cost. Settlers coaxed a living out of the land with blood, sweat, and muscle, either their own or someone else's. Hardiness, determination, ingenuity, courage, and a strong back were all required. In history and folklore, American cultural heroes embody these admired characteristics, from the inventive Benjamin Franklin, courageous Tecumseh, and self-reliant Daniel Boone to the intrepid Amelia Earhart and undaunted Rosa Parks. Despite a history replete with racial, ethnic, gender, and other forms of oppression, Americans are proud of their "self-made" men and women.

On the other hand, our political processes require a spirit of community. Our reliance on cooperation is evident in everything from the barn-raisings and quilting bees of our rural past to the jury duty of our judicial system and the volunteer spirit that brings communities together in times of crisis to do what needs to be done. By preference a nation of do-it-yourselfers, Americans have traditionally been cooperative when pressed to accomplish the bigger jobs of protecting their communities, assisting those in need, and running a democracy.

The balance between the spirit of individualism and cooperation for the greater good is never perfect. As Singer and Kimbles point out, "Individuation and wholehearted participation in the life of the group do not fit together easily or naturally" (Introduction 4). In times of stress and division, and even in times of prosperity and complacency, the threads of common good may be stretched or even ripped apart. The 1980s, for example, famous as the "Me Decade," were a prosperous time noted by many commentators to be lacking in social activism but heavy on wealth accumulation and materialism. In post-9/11 America, sharp divisions on the best way to counter terrorism, ensure security, and conduct foreign relations seemed to cleave the country in two, following on the heels of a historically close presidential election in 2000 (and succeeded by another in 2004). Since then, the media have talked incessantly of the rifts in American political and social life, political discourse has become shrill and at times uncivil, the spirit of bipartisanship in national government has increasingly become a thing of the past, and the divide between rich and poor seems greater than ever. Social psychologist Jonathan Haidt, writing on a divided America in The Righteous Mind, notes that

America's political class has become far more Manichaean since the early 1990 s....

Before 1995, congressmen from both parties attended many of the same social events on weekends; their spouses became friends; their children played on the same sports teams. But nowadays most 


\section{Journal of Jungian Scholarly Studies 4}

congressmen fly to Washington on Monday night, huddle with their teammates and do battle for three days, and then fly home on Thursday night. Cross-party friendships are disappearing; Manichaeism and scorched Earth politics are increasing. (362-63)

Could it be that with the end of the Cold War, much of the shadow once projected outward has now fallen inward, so that Americans see it more readily in each other? Could this be why so many of our battles are now internal? Indeed, former U.S. Senator Bill Bradley has implicated the Cold War and its either/or mentality in enforcing a dualism in American psychology that has "infected our politics at all levels of thinking" (24).

\section{Fragmentation and Diversity}

In assessing the social and political landscape over the last twenty years, one finds that sociologists and political scientists do not agree on the extent to which a "culture war" or fragmenting of society has actually occurred (Fischer and Mattson 437; Abramowitz and Saunders 543). Some commentators believe that the stridency in political discourse is an inevitable by-product of democracy and a sign of its proper working (Purdum 1); other studies have indicated that the perception of a divided society may be greater than the reality (Morrill, Knopp, and Brown 29). Still others say that political divisiveness has been even greater in the past (for example, during the Civil War) and that uniformity of belief and lack of conflict create problems of their own (Fischer and Mattson 436-37), a point with which Singer and Kimbles would likely agree.

Much seems to depend on the way divisiveness is defined. A 2014 study by the Pew Research Center finds that, compared with twenty years ago, significantly more Americans are now consistently liberal or consistently conservative in their political views and that these views correspond more closely to Democratic or Republican party affiliations. Furthermore, the most partisan members of both parties are likely to view the other party's policies as "so misguided that they threaten the nation's well-being." The Pew study finds that while most Americans have a mix of views and support political compromise, they often "remain on the edges of the political playing field, relatively distant and disengaged, while the most ideologically oriented and politically rancorous Americans make their voices heard through greater participation in every stage of the political process."

The perception of a divided America has permeated the collective consciousness and certainly seems evident at the highest levels of leadership, where cooperation on such issues as national security, gun control, environmental policy, and more has, as of mid-2014, come to a virtual standstill. Ideological differences over such flashpoint issues as abortion and gay marriage - exacerbated by political wrangling during recent elections-point to some fundamental divisions among Americans, conditioned by cultural complexes (Singer 163-64). Conflicts over 


\section{Hackworth}

basic values like personal rights are often the most contentious type of conflict, and debates on these issues have been highly visible, not to mention exploited, in recent years (Morrill, Knopp, and Brown 28).

The perception of a society divided, even if partly exaggerated, has likely had the force of a self-fulfilling prophecy at times. In any case, widely divergent opinions and beliefs are a fact of American life. To add to the complexity, the United States is becoming increasingly diverse in terms of ethnicity, race, and other factors and is predicted to consist of a "majority-minority" society by 2043 (Lichter 359-61). America has been called a melting pot, but that chemistry has always been questionable, and in recent years, more and more subcultures, points of view, and value systems have emerged and clashed. Rather than leading to economic and social parity, greater diversity, Lichter asserts, could lead to more disparity and friction as entrenched powers attempt to hold onto their advantages and emerging subgroups struggle for a greater share.

While political conflict has lately gotten a bad name, especially in light of the Federal government shutdown debacle of 2013, it may, in the long run, be both unavoidable and necessary, say Singer and Kimbles. "A potential way of understanding the process of individuation in the group," they write, "is to think of it as the gradual working through and integration of the group's core cultural complexes over its lifetime ..." ("Cultural Complex and Individuation" 237). This integration necessitates a thorough airing of contending viewpoints as well as "engagement, compromise, reconciliation, and healing after generations of recurring battle" (Singer 165). While Jung did not fully develop his thinking on cultural complexes, post-Jungians such as Singer, Kimbles, and Brian Feldman now see group individuation as a vitally important ingredient of social transformation. In propounding post-Jungian theories of boundaries and "psychic skin," Feldman describes permeability, the capacity to integrate more and more perspectives into conscious experience, as the quality that opens the way for

change, transformation and growth, for the inflow of new ideas and new discourses. . . . This capacity for a primary social skin function helps both the individual and the groups in their evolution of identities. ... Within the context of cultural complexes, cultural identities may be forged and transformed as the tensions between past history, collective memory, and present social discourses are encountered. (257)

From this perspective, some of America's current fractiousness is evidence of growth, even though the process creates stress and loss of equilibrium. This tumult is postmodernism with a vengeance: the noisy emergence of multiple narratives in 


\section{Journal of Jungian Scholarly Studies 6}

a country searching for new guiding myths to encompass a much larger, more varied, and more inclusive society than existed in the past.

In the midst of this maelstrom of racial, gender, religious, economic, and values-based conflict, a countering tendency to establish harmony has arisen, as Jung, in "The Practical Use of Dream-Analysis," predicts it must, without the conscious awareness of those caught up in the struggle. Jung describes compensation as a necessary part of normal psychic functioning:

The psyche is a self-regulating system that maintains its equilibrium just as the body does. Every process that goes too far immediately and inevitably calls forth compensations, and without these there would be neither a normal metabolism nor a normal psyche. In this sense we can take the theory of compensation as a basic law of psychic behaviour. Too little on one side results in too much on the other. ( $C W 16$, par. 330)

Jung explains that a one-sided conscious attitude is a danger that can only be corrected by acknowledging repressed attitudes, thoughts, and experiences. The collective psyche can be unbalanced by excessively privileging one value, such as freedom, at the expense of other values, such as cooperation and responsibility. Compensation calls attention to previously unrecognized or undervalued tendencies, beliefs, and attitudes.

\section{Searching for a Center, If There Is a Center}

In "Conscious, Unconscious, and Individuation," Jung describes a psychological quest for wholeness, "the process by which a person becomes a psychological 'in-dividual,' that is, a separate, indivisible unity or 'whole"” ( $C W 9 \mathrm{i}$, par. 490). There is, however, a paradox in this process, as Jung explains in "Archetypes of the Collective Unconscious," since the Grail of this quest, the center or the Self, is located both within and without:

A more or less superficial layer of the unconscious is undoubtedly personal. I call it the personal unconscious. But this personal unconscious rests upon a deeper layer ... [that] I call the collective unconscious. I have chosen the term "collective" because this part of the unconscious is not individual but universal; in contrast to the personal psyche, it has contents and modes of behaviour that are more or less the same everywhere . . . and thus constitutes a common psychic substrate of a suprapersonal nature which is present in every one of us. ( $C W 9 \mathrm{i}$, par. 3)

Whether at the individual or the group level, the individuation process is much the same. Emma Jung and Marie-Louise von Franz describe the "widening of the continually changing horizon of awareness" of individuation, in which a meaningful connection with this greater and more inclusive consciousness-the 


\section{Hackworth}

universal, archetypal Self beyond the personal ego-gradually emerges. They speak of "manifestations of the Self, arising from the unconscious ... distinguished by circular and square forms," which Jung himself calls mandalas (98-99).

Here we have the key to a centuries-old symbol whose current popularity might otherwise prove puzzling: the medieval labyrinth. This unicursal labyrinth, with its single, circuitous but clearly delineated path, is an image that encompasses both shared and individual experience. The unicursal labyrinth is distinguished from a multicursal labyrinth (or maze) by having only a single (though winding) path to its center. While a maze may have little or no symmetry and may not even have a center, a medieval labyrinth usually has both.

Although the multicursal maze has often been used in literature and philosophy as an apt metaphor for modern life, in all of its divergence, alienation, and isolation (Peyronie 714-19; Hackworth 20-21; Baker 83), unicursal labyrinths, notably those based on the design of the medieval labyrinth in France's Chartres Cathedral, have enjoyed a great resurgence over the last twenty years. This elegant, circular, stylized labyrinth, with its curving pathway moving gracefully toward a pronounced center, closely resembles a mandala. Thus it introduces a symbolic counterweight to divisiveness, social fragmentation, and lack of cohesion.

While the current interest in labyrinths is by no means limited to America, the movement received its impetus in the United States through the efforts of Lauren Artress, an Episcopal canon whose decision in 1991 to use the labyrinth as a meditative tool was inspired by a visit to Chartres and the work of other researchers, including author Jean Houston and architect Keith Critchlow (Artress $2,4)$.

\section{Significance of the Mandala}

Jung, von Franz, and Aniela Jaffé have all pointed out that mandala forms are naturally appearing symbols of healing and integration that surface in dreams and artistic productions ( $C W 14$, par. 660; von Franz 230; Jaffé 266-69). In his "Commentary on 'The Secret of the Golden Flower," Jung describes mandalas as circular symbols incorporating a quaternary or cruciform design ( $C W 13$, par. 31). They often have a central sun, star, flower, or cross, expressing a dynamic point of origin and "the ultimate unity of all archetypes as well as of the multiplicity of the phenomenal world" ( $C W$ 14, par. 661). In "Concerning Mandala Symbolism," Jung says that their appearance "serve[s] to produce an inner order," such that "they often follow chaotic, disordered states marked by conflict and anxiety. They express the idea of a safe refuge, of inner reconciliation and wholeness" ( $C W 9 \mathrm{i}$, par. 710). 


\section{Journal of Jungian Scholarly Studies 8}

Jung saw the similarity between medieval, Christ-centered mandalas in manuscripts and rose windows, the mandalas of his patients, and those of the Eastern religions; in all of these, he found cross-cultural vindication for his views on the importance of the mandala as an organizing principle ( $C W 11$, pars. 136-38, 945-48). Referencing the mandalas produced by Jung's patients during analysis as well as those Jung himself drew during World War I, V. Walter Odajnyk explains that they "appear mostly in situations of psychic disorientation or panic" and that Jung believed his own mandalas "helped him maintain his psychic equilibrium" (22). Jung's insight that "everything points toward the center," derived from his mandala drawings, gave him, in his own words, "stability" and "inner peace" (Memories 197). Odajnyk notes that mandalas drawn by modern Westerners often have an empty center or consist of circles "sectioned into quadrants and other radial divisions" (20-21) — not unlike the Chartrain labyrinth, with its cross arms and open center.

If political polarization, growing diversity, and fragmentation are facts of contemporary life, the labyrinth, as a mandala, suggests a focus on recentering and discerning a common path. In keeping with Feldman's ideas of permeability, the labyrinth is not a closed circle: its single path leads from the outside to the center, and from the inside out. Thus, it symbolizes openness and movement as well as wholeness; it is a dynamic, not a static, image.

\section{A Medieval Image Goes Modern}

Since the early tenth century, the Christianized unicursal labyrinth, created by monks, has been circular (indicating divine perfection) with a cruciform pattern in its lines (Wright 21,23) and a circle or rosette at the center-but the labyrinth is much older. An ancient form of unicursal labyrinth, most closely associated with Europe and the Mediterranean world, consisted of seven elliptical circuits "unchecked" on three sides, with an unexceptional center. This "classical labyrinth" has been found in petroglyphs dating back to Neolithic times (Saward, Labyrinths 20). Although its exact origin and original meaning are unknown, theories connecting it with ritual, nature, warfare, and the protection of cities have been advanced. While it is not a maze, the relationship of this labyrinth to Theseus, Ariadne, the Minotaur, and the labyrinth of Greek legend has been much debated. It is possible that several traditions, including an ancient ritual dance, natural structures such as caves, the existence of large, impressive, and confusing buildings (like the palace at Knossos), the myth, and the classical design itself-originally separate ideas-became somehow intertwined in the distant past (Kern 25-26; Saward, Labyrinths 20-23).

The "classical design" (and variations) eventually became a common motif on coins, pottery, and other surfaces and survived into medieval times, where it appeared in manuscripts, churches, and landscape labyrinths of stone and turf 


\section{Hackworth}

(Saward, Labyrinths 42-47, 82-103, 120, 138). Monks eventually changed the elliptical design, rounding it, increasing the number of circuits from seven to eleven (eleven signifying the world's imperfection), and adding the distinct cruciform pattern (by creating "checked" courses on three additional sides) to give the labyrinth a Christian meaning (Wright 20-27). While the exact uses of this labyrinth during the Middle Ages are, like much of its history, debatable, it was a fairly common design element in churches, particularly in France and northern Italy. It typically appeared on floors and pavements, as in the still existing example at Chartres. Many church labyrinths were later destroyed as the concept fell out of favor, although labyrinths also appeared in other forms, as I have discussed in Solved by Walking, including garden mazes, illustrations, literature, and even dance and music (141-86). A nineteenth-century revival renewed interest in medieval labyrinths, and several were installed in English, French, and other European churches at that time (Saward, Labyrinths 112-17).

\section{Archetypes of the One and the Many}

In classical mythology, the Minotaur and the labyrinth may have represented primordial nature mysteries once approached through solar rituals (Kern 31-33) transformed into a tale of heroism. Since then, the labyrinth has appeared in many literary guises to represent a quest or a search for truth. As I have argued elsewhere, the distinction between the two types of labyrinths is crucial: its multicursal or mazelike form, reflected in the journey of the Grail knights, Childe Roland, the crew of the Pequod in Moby-Dick, and William of Baskerville in Umberto Eco's The Name of the Rose, and its unicursal form, in Dante's The Divine Comedy, John Bunyan's The Pilgrim's Progress, and many medieval labyrinths, signify different kinds of experience. The first, a trip into the unknown in which all bets are off, has a choice of paths, and the second, a guided tour, takes travelers into territory that has already been mapped (16). From Plato's philosophical labyrinth of error in Euthydemus to the Christ-centered medieval labyrinths in manuscripts and churches; from the garden mazes of the Renaissance to the spiritual labyrinths of seventeenth- and eighteenth-century literature and art; from the dark, labyrinthine plots of Edgar Allen Poe to the labyrinths of knowledge of Jorge Luis Borges and Eco, labyrinths have appeared time and again as signifiers of either confusion or the certain path. I argue that both are searches for truth, but they use different approaches, one based on individual experience and the other on tradition, doctrine, or common wisdom.

These very different strategies form, across time, a philosophical "oscillation" between "structure" and creative "emergence" similar to the one described by religious studies scholar Mark C. Taylor, who writes that "such thought is 


\section{Journal of Jungian Scholarly Studies 10}

perpetually transitory and forever nomadic. It is neither simply this nor that, here nor there, inside nor outside" (11). This "betwixt 'n' between" status of believers and seekers, "[s]uspended between the loss of old certainties and the discovery of new beliefs" (5), corresponds in some ways to the secular situation of the United States today, caught between old ways of defining itself and new ones now emerging.

If Americans are indeed seeking a social, political, and philosophical common ground, the appearance of the labyrinth may be one indicator of that search. Although the labyrinth is perceived mostly as a tool for individual use, its resemblance to a mandala implies a broader significance perhaps not fully recognized. Odajnyk notes that "the unconscious is limited in what it can do. The symbols through which it speaks must be consciously interpreted and applied. Otherwise the symbols fall like apples to the ground, where there is no one to pick them up and eat them" (21).

\section{From Round Table to Contemporary Quest}

As we have seen, the medieval Queste del Saint Graal has been an especially formative myth for the modern West (Campbell, Creative Mythology 36-37). In it, knights of the Round Table enter the woods and search for the Grail, each in the place he judges to be right. The Quest results in the breakup of the Round Table (another mandala) and represents a shift from the unity of a shared vision and purpose to the solitary path of individual striving. There is no established path, and most of the knights take numerous wrong turns, "inevitably to err," to borrow Taylor's terminology. In protomodern fashion, Queste depicts individuals searching for truth, as I have suggested, armed only with their own abilities and conscience (16-17). Their challenges may sound very familiar to their modern counterparts struggling in a contemporary quicksand of changing values when strong communal ties are absent.

In Occidental Mythology Campbell explains how modernity measures meaning against the yardstick of individual experience. He calls the Grail Quest a trackless way, declaring that redemption of the wasteland is the errand of every individual once the certainties of tradition have been shaken and "there is no more any fixed center, any Mecca, Rome, or Jerusalem" (522). Jacques Attali concurs, arguing in The Labyrinth in Culture and Society that the maze is the proper metaphor for modern life and its intricate systems, including social networks, communications, the economy, and the World Wide Web (xxiii-xxiv). From this perspective, each individual is in a maze that interlocks with the mazes of others to form a larger network of mutual influence and tension.

Postmodernism's predominant intellectual position is an openness that recognizes multiple points of view, and its literature has explored the farthest reaches of individualism, seeing the maze from a subjectivist viewpoint in which 


\section{Hackworth}

the concept of a single "center" may not even apply (Hackworth 20-21; Baker 84-85). A maze walker quoted by Artress describes her experience of mazes as being "effortful" in a way that unicursal labyrinths are not:

As a truth seeker and pilgrim for many years, it was amazing to be on a journey that immediately revealed itself to me as a metaphor for my life. I always enjoyed mazes, knowing there was ultimately a way out but having to find it was a game I enjoyed. As I got older, the game became less fun, the mazes more twisted, the challenges more exhausting: another metaphor for my life. The labyrinth is safe, effective and inspiring. (qtd. in Artress 51-52)

As this example demonstrates, a maze is a byword for complexity and can even serve to illustrate individuation - particularly in its early stages - although today "maze" has connotations of alienation and a crisis of meaning.

So it was that in 1991, Artress became interested in medieval labyrinths after attending a workshop and then seeing the labyrinth at Chartres. She was conscious of the powerful effect-initially unsettling but increasingly "grounding"-the symbol had on her and began to think about introducing it to others as a meditative tool (Artress 1-7). The fact that her efforts to promote the labyrinth jump-started a movement suggests that, though she may have been the catalyst, the culture was ready for the concept, esoteric though it may have been.

As previously noted, medieval labyrinths (and variations, including the classical design of which the medieval style is an outgrowth) now appear across the United States in settings ranging from churches and parks to hospitals and museums; they may be painted, tiled, paved, woven into a carpet, constructed of canvas, or cut into a lawn and are usually designed to be walked on. Artress asserts that since the 1990s, the medieval labyrinth has entered public consciousness as a "blueprint for transformation" rather than "an oddity," as it was at one time (x). Moreover, labyrinths are not limited to meditative and ritual use; they also appear in secular and recreational settings and are often noteworthy for their ornamental or artistic value.

\section{What Is the Appeal?}

Advocates frequently describe benefits associated with walking in labyrinths. Helen Curry extols the labyrinth's ability to "help bring us into balance, giving us a sense of wholeness that is much needed for all of us whose lives ache with lopsided discomfort" (8). Saward describes an "increased calm" reported by labyrinth walkers as well as a "chance to walk the same pathway travelled by our ancestors, indeed to tread in the very same footsteps of countless visitors before us" (Labyrinths 205). Robert Ferré, who has installed over a thousand labyrinths 


\section{Journal of Jungian Scholarly Studies 12}

professionally, says that the current revival reveals an archetypal appeal, since the labyrinth "keeps appearing and reappearing in human experience," adding that, "Far from being a fad, I think the labyrinth appears periodically when it is needed. Our modern times are so far out of balance that a tool is needed that can help restore equilibrium" (11).

I suggest that the popularity of the unicursal labyrinth as a tool for meditation and recreation here in the United States expresses a wish to walk a heroic, individual path and connect this path to a common purpose. The two tendencies, though sometimes at odds, are not necessarily opposed. An emphasis on individual freedom can coexist with the need for a connection to something greater, a supposition given weight not only by Jung but also by the theory of embedded individualism described by Thomson (652-53), who has surveyed the changing relationship of the individual to American society across several decades of the twentieth century. A responsive, embedded individualism, though difficult to achieve and maintain, could be the balance America has long struggled to attain, as others, including James Hillman, have suggested (“"Man”" 59).

One labyrinth walker describes the paradoxical sense of individuality and commonality she experienced in walking a labyrinth: "It is amazing to me that the 'same' labyrinth ... generates an incredible variety of experience and insights for each individual, just as we each walked 'our' path in a unique way" (qtd. in Artress 31). This description corresponds to what happens in individuation, which begins with finding one's own identity and matures into a growing connection with universal concerns.

\section{Finding the Middle Way}

Perhaps our continuing difficulty in balancing individual and community interests results partly from limitations in the way our culture defines the individual. Hillman challenges us to rethink the common American style of individualism, steeped in consumerism and "political passivity" and lacking in imagination and "aesthetic response" to the world ("Aesthetic" 144). He writes, "If we . . seek ways to connect psychotherapy with social change, we must also reimagine 'case material.' If we wish to release depth psychology from its confines in human personality and return study of soul, logos of psyche, to the larger world beyond the human, we must also draw our cases from pathologies in the culture ... ("Psychology" 110). Hillman's sense of individuality interiorizes community, seeing the individual not only embedded within a social network, as Thomson and others have described, but also possessed of an interior sense of belonging. Hillman does not so much repudiate individualism as attempt to return us to the sense of citizenship he believes the founders of American democracy intended. He speaks of "widely differing individualities . . . each of whom is in pursuit of differing happiness and defends private domains" ("Right" 88). This style of individualism 


\section{Hackworth}

implies a heady brew of diverse outlooks and opinions, very much like the contemporary scene:

The differing individual imaginations manifesting themselves as differing religious concerns, geographical loyalties, philosophical commitments, and economic goals must be fundamentally affirmed, not dissolved in the ogre's cauldron called America, the Melting Pot. The founding documents assume these inalienable differences of imagination in the citizenry and so the Constitution had to provide means for negotiating differences-elective, judicial, legislative - as well as be amended by a Bill of Rights. ("Right" 88-89)

The type of inclusive polis Hillman describes may exist only imperfectly (and at best be a contentious affair), but the ever-increasing diversity of American society makes its realization more urgent. As Americans discover fewer commonalities of ethnicity, religious belief, and modes of life, the nation's founding principles of equality and opportunity may be the mechanism that provides a sense of national identity and shared ground. Without such a center, growing social divisions could result in unrest, increasing alienation among groups, and conceivably an actual fracturing along geographic or cultural lines.

\section{The Paradox of the Labyrinth}

It is hardly surprising that mazes of one type or another, with their built-in possibilities of confusion, resonate with the postmodern, multicultural experience. On the other hand, there are now more unicursal, medieval-style labyrinths being built than ever before, according to Saward, whose research encompasses the history of the subject from antiquity to modern times ("Re: Question About U.S. Labyrinths").

The contemporary fascination with the unicursal labyrinth and its proliferation in both public and private places indicates that, despite the maze of modern lifeand maybe because of it-finding a center is still a desirable goal for many. This concern for a center suggests a wish for unity underlying the diverse wanderings of our highly individualistic and "self-reliant" society. Some psychologists, such as Edward E. Sampson, have questioned the possibility of successfully joining individualism and a strong communal identity in the same society, seeing them as too fundamentally different to admit of integration ("Debate" 21; "Challenge" 919); others, including Hillman, hold out the hope that the two tendencies can be balanced, albeit with difficulty. In light of this debate among American psychologists over the relationship of the individual to society, the reappearance of 


\section{Journal of Jungian Scholarly Studies 14}

the medieval labyrinth in recent years, redolent of wholeness and unity, is perhaps no accident.

Campbell and Jung agree that myths are both reactionary and revolutionary, a condition Wendy Doniger discusses in The Implied Spider (107). Symbols can become rigid, the way some aspects of the Christian church and its labyrinth became dogmatic in the late Middle Ages, a state Artress characterizes as "suffocating religiosity" (115). The maze, with its many choices, then began to represent not imprisonment but freedom, until at long last, it, too, by a process of reversal, became stale and confining (Hackworth 45). Prolonged pursuit of an individual path without a sense of connection to common goals and larger purposes may lead to selfishness and myopia, as it does when, in pursuit of the American dream, one strays too far into materialism (which Singer [166] has identified as another of America's most problematic cultural complexes).

\section{Conclusion}

In the contemporary world, with many voices demanding a hearing, it may be as important to recognize what all have in common as to acknowledge what makes each individual unique. America has commonly held values, chiefly, the belief in equality, freedom of thought and expression, and self-determination, so a centering point exists, at least in theory. When community is interiorized, says Hillman, "Then to ask in a therapeutic session about the political is to ask about Self. Then to pursue self-development requires community pursuits. Then one turns for confirmation of one's self-steering course - am I on track or off, am I repressing, am I centered?- to the actual community of one's actual life" (“"Man"” 59).

Doniger elucidates the dangers of pluralism carried to extremes. As she puts it, "The emphasis on individual cultures [or individual truths] . . may lead to problems of infinite regress. . . This emphasis tends to generate a smaller and smaller focus until it is impossible to generalize even from one moment to the next ..." (67). This level of specificity makes a comparison of perspectives difficult. If they really have nothing in common, Doniger points out, there is no way to find underlying patterns and connections in what is merely a miscellany of unrelated experiences.

The unicursal labyrinth, while looking the same as it did a thousand years ago, symbolizes something different to Americans encountering it today than it did to a medieval churchgoer. While we do not know the specifics of the use of the labyrinth in the Middle Ages, the realities of modern life have encouraged a reflective, individualized approach to its use. It is no longer the single path to righteousness in a Christ-centered belief system or even the path of sin in a fallen world, alternatives discussed by literary critic Penelope Reed Doob in The Idea of the Labyrinth. It now represents the individual pursuit of meaning as well as the "universal" condition. Having experienced a welter of competing viewpoints, 


\section{Hackworth}

Americans of the twenty-first century have a new task: recognizing the possibility of multiple truths while seeking the place where everyone meets. This search for connection is important. The health of our diverse society may depend on connecting the individual in a meaningful way to other individuals and the community - as well as to the larger world.

Should Americans lose hope in the face of the seemingly intractable political, economic, and social storms that have divided them in recent years? Despite evidence to the contrary, the answer is "perhaps not," if the appearance of the labyrinth mandala is any gauge of an impulse toward wholeness. America may weather its storms and become a stronger and more integrated society to the extent that it acknowledges its own cultural complexes and shadow, reaches out to its adversaries in a spirit of problem solving, and works toward inclusiveness in the form of greater economic and social justice. This is a tall order, most would agree - but not impossible. One need not walk a labyrinth to accomplish these goals, but its presence in our midst is a reminder: while America is a nation of individuals, its challenge is to work continually toward forming, if not a more perfect union, then at least a society that accommodates the tension of differences while itself remaining whole.

\section{Works Cited}

Abramowitz, Alan I., and Kyle L. Saunders. "Is Polarization a Myth?" The Journal of Politics 70.2 (2008): 542-55. Academic Search Alumni Edition. Web. 21 May 2013.

Artress, Lauren. Walking a Sacred Path: Rediscovering the Labyrinth as a Spiritual Practice. Rev. ed. New York: Riverhead, 2006. Print.

Attali, Jacques. The Labyrinth in Culture and Society: Pathways to Wisdom. Trans. Joseph Rowe. Berkeley: North Atlantic, 1999. xii-xxviii. Print.

Baker, Rob. “A Modern Metaphor.” Parabola 17.2 (1992): 83-87. Print.

Bradley, Bill. "Reflections on Myth, Politics, and Leadership." The Vision Thing: Myth, Politics and Psyche in the World. Ed. Thomas Singer. London: Routledge, 2000. 23-27. Print.

Campbell, Joseph. The Masks of God: Creative Mythology. New York: Penguin Compass, 1976. Print.

---. The Masks of God: Occidental Mythology. New York: Penguin Compass, 1976. Print.

Curry, Helen. The Way of the Labyrinth: A Powerful Meditation for Everyday Life. New York: LarkPenguin Compass, 2000. Print.

Doniger, Wendy. The Implied Spider: Politics \& Theology in Myth. New York: Columbia UP, 1998. Print. Amer. Lectures on the Hist. of Religions. Amer. Acad. of Religion New Series 16.

Doob, Penelope Reed. The Idea of the Labyrinth: From Classical Antiquity Through the Middle Ages. Ithaca: Cornell UP, 1990. Print.

Feldman, Brian. "Towards a Theory of Organizational Culture: Integrating the 'Other' from a PostJungian Perspective.” Singer and Kimbles 251-61. 


\section{Journal of Jungian Scholarly Studies 16}

Ferré, Robert. Church Labyrinths: Questions \& Answers Regarding the History, Relevance, and Use of Labyrinths in Churches. St. Louis: Labyrinth Enterprises, 2001. Print.

Fischer, Claude S., and Greggor Mattson. "Is America Fragmenting?" Annual Review of Sociology 35.1 (2009): 435-55. Web. 22 May 2013.

Franz, M.-L. von. “The Process of Individuation.” Jung, von Franz, and Freeman 157-254.

Hackworth, Mary. Solved by Walking: Paradox and Resolution in the Labyrinth. N.p.: CreateSpace, 2012. Print.

Haidt, Jonathan. The Righteous Mind: Why Good People Are Divided by Politics and Religion. 2012. New York: Vintage-Random, 2013. Print.

Hillman, James. City \& Soul: Uniform. Ed. Robert J. Leaver. Vol. 2. Putnam, CT: Spring, 2006. Print.

Jaffé, Aniela. "Symbolism in the Visual Arts." Jung, von Franz, and Freeman 255-322.

Jung, Carl G. The Collected Works of C. G. Jung. Ed. Sir Herbert Read et al. Trans. R. F. C. Hull. $2^{\text {nd }}$ ed. Princeton: Princeton UP, 1953-79. Print. 20 vols. Bollingen Series 20.

---. Memories, Dreams, Reflections. Ed. Aniela Jaffé. Trans. Richard and Clara Winston. Rev. ed. 1973. New York: Vintage-Random, 1989. Print.

Jung, Carl G., M.-L. von Franz, and John Freeman, eds. Man and his Symbols. New York: LaurelDell, 1968. Print.

Jung, Emma, and Marie-Louise von Franz. The Grail Legend. Trans. Andrea Dykes. $2^{\text {nd }}$ ed. Princeton: Princeton UP, 1998. Print. Mythos Series.

Kern, Hermann. Through the Labyrinth: Designs and Meanings Over 5,000 Years. Ed. Robert Ferré and Jeff Saward. Trans. Abigail H. Clay, Sandra Burns Thomson, and Kathrin A. Velder. Munich: Prestel, 2000. Print.

Lichter, Daniel T. "Integration or Fragmentation? Racial Diversity and the American Future." Demography 50.2 (2013): 359-91. Springer Science+Business Media. Web. 25 May 2013.

Morrill, Richard, Larry Knopp, and Michael Brown. "How Real are Red America and Blue America?” FOCUS on Geography 50.1 (2007): 22-29. Academic Search Alumni Edition. Web. 11 May 2013.

Odajnyk, V. Walter. Gathering the Light: A Psychology of Meditation. Boston: Shambhala, 1993. Print.

Pew Research Center. "Political Polarization in the American Public." Pew Research Center for the People \& the Press. Pew Research Center, 12 June 2014. Web. 13 June 2014.

Peyronie, André. “The Labyrinth.” Companion to Literary Myths, Heroes and Archetypes. Ed. Pierre Brunel. Trans. Wendy Allatson, Judith Hayward, and Trista Selous. London: Routledge, 1992. 685-719. Print.

Purdum, Todd S. "The Year of Passion.” New York Times 31 Oct. 2004: 1+. NYTimes.com. Web. 4 May 2013.

Sampson, Edward E. "The Challenge of Social Change for Psychology: Globalization and Psychology's Theory of the Person." American Psychologist 44.6 (1989): 914-21. Ovid PsycARTICLES. Web. 22 May 2014.

---. "The Debate on Individualism: Indigenous Psychologies of the Individual and Their Role in Personal and Societal Functioning." American Psychologist 43.1 (1988): 15-22. Ovid PsycARTICLES. Web. 22 May 2014.

Saward, Jeff. Labyrinths \& Mazes: A Complete Guide to Magical Paths of the World. New York: Lark-Sterling, 2003. Print.

---. “Re: Question About U.S. Labyrinths.” Message to the author. 3 July 2013. E-mail. 


\section{Hackworth}

Singer, Thomas. "A Personal Meditation on Politics and the American Soul.” Spring 78 (2007): 149-75. Print.

Singer, Thomas, and Samuel L. Kimbles. "The Cultural Complex and Individuation of the Group." Singer and Kimbles 237.

Singer, Thomas, and Samuel L. Kimbles, eds. The Cultural Complex: Contemporary Jungian Perspectives on Psyche and Society. Hove: Brunner-Routledge, 2004. Print.

---. Introduction. Singer and Kimbles 1-9.

Taylor, Mark C. Erring: A Postmodern A/theology. Chicago: U of Chicago P, 1987. Print.

Thomson, Irene Taviss. "From Conflict to Embedment: The Individual-Society Relationship, 1920 1991." Sociological Forum 12.4 (1997): 631-58. Academic Search Alumni Edition. Web. 25 Mar. 2013.

Wright, Craig. The Maze and the Warrior: Symbols in Architecture, Theology, and Music. Cambridge: Harvard UP, 2004. Print. 